Article

\title{
Stimulating and Educating Engineers to Innovate through Individual Continuous Learning
}

\author{
Jing Liu ${ }^{1,2}$, Xiaokang Zhao ${ }^{1, *}$ and Chunliang Zhao ${ }^{3}$ \\ 1 Glorious Sun School of Business and Management, Donghua University, Shanghai 200051, China; \\ liujing1007@163.com \\ 2 School of Business and Management, Henan University of Engineering, Zhengzhou 451191, China \\ 3 Zhengzhou Branch, China Ever Bright Bank, Zhengzhou 450008, China; zcl209@163.com \\ * Correspondence: zxk@dhu.edu.cn
}

Received: 29 November 2019; Accepted: 19 January 2020; Published: 23 January 2020

\begin{abstract}
Based on the self-determination theory and planned behavior theory, this paper studied the mechanisms of innovative behavior driven by engineers' individual continuous learning. It was found that individual continuous learning can promote engineers' innovative behavior and that career planning and self-efficacy play a dual mediating role in the effect that individual continuous learning has on bringing about innovative behavior. In addition, engineers' risk tolerance positively increases the effect of individual continuous learning on self-efficacy. Furthermore, the organizational climate affects the innovative behavior brought about by engineers' individual continuous learning. Therefore, we make some suggestions for vocational education and the management of engineers. It is necessary for managers to develop strategies to encourage engineers to continue learning both inside and outside the organization. Organizations need to support engineers in improving their professional skills and abilities so as to enhance self-efficacy. Managers need to pay attention to career planning for engineers, assist them in career planning, and help them to achieve their career goals through training or related courses. Managers also need to allow engineers to make mistakes and strengthen risk education for engineers. Managers need to create a climate of innovation in which members support and cooperate with each other so that engineers can implement innovative behavior more effectively and achieve innovative goals.
\end{abstract}

Keywords: individual continuous learning; self-efficacy; organizational climate; risk tolerance; engineer education

\section{Introduction}

The impact of emerging technologies on traditional industrial structure and the operation mode has brought about changes that every organization and its members cannot avoid, and adapting to the environment has become an inevitable rule of organizational survival. Fortunately, engineers constantly promote the progress of science and technology through incremental innovation and radical innovation. If we know that engineers are "turning dreams into reality", it is incumbent upon educators to support engineers in developing their ability to influence the future [1]. Moreover, with the use of artificial intelligence in industry, some companies internalize digital technology and combine digital employees and engineers with different ways of thinking and learning to enhance core competitiveness so as to stimulate innovation [2]. Nevertheless, there are two important issues that deserve attention. The first one is the factors that affect engineers' innovative behavior. The second issue is how to carry out engineering education to promote engineers' ability to innovate. An important aim of engineering education is to equip engineers with the ability to resolve complex and unexpected problems using methods such as individual continuous learning, career planning, risk tolerance, and self-efficacy. The 
aim is particularly important in engineering education since engineers' innovation plays the prominent part in the business performance and social progress.

Enterprises are already learning from suppliers and can benefit from that information. However, due to the limitations of enterprise size and available resources, innovation in manufacturing or delivery processes is restricted by multiple factors [3]. Educators should support the development of engineers' innovative ability and adopt teaching methods, such as activities, courses, and curricula, to improve their innovative ability [4]. Innovative leadership and win-win innovation culture influence workplace innovation. Organizations can also improve workplace innovation and career satisfaction by accrediting their engineers [4]. The results highlight the importance of providing opportunities for engineers to participate in creative and innovative projects so as to improve their careers. Fairlie and Robb found that, in many small enterprises, technical workers form the backbone of their business and the productivity of these knowledge workers can be divided into six categories: systematization and structuralization, learning motivation, attention, output, punctuality, and communication [5]. Eddy et al. regarded self-efficacy and skill sets as a subset of the overall set of abilities required by system engineering and found that the self-efficacy of system engineers can be influenced by a regimented education plan [6]. Therefore, in many countries, educators and managers have used the structured curricula to train engineers, expecting them to acquire technical knowledge, professional skills, and work experience $[7,8]$.

In summary, scholars have oft paid attention to the factors that affect engineers' ability to innovate, but how do these factors affect each other? Unfortunately, little research has been done on this issue. Many organizations have noticed the positive effect of individual continuous learning on innovation. However, there are few studies on how to motivate engineers to innovate by using individual continuous learning as the driving force. Some scholars give suggestions on the curriculum designs of engineers' continuous learning programs based on the research they have done $[7,8]$, but most engineering education does not adequately discuss how engineers innovate through individual continuous learning. This paper makes up for this gap by answering the following questions: $(\mathrm{Q} 1)$ Does individual continuous learning promote engineers' innovative behavior? (Q2) Do self-efficacy and career planning mediate the relationship between individual continuous learning and engineers' innovative behavior? (Q3) Does risk tolerance have an impact on the relationship between individual continuous learning and self-efficacy? (Q4) Does an organizational climate affect the mechanism of engineers' innovative behavior? (Q5) By what means should one promote engineers' grassroots innovation through engineering education?

In order to answer the above questions, we selected engineers in several provinces of mainland China as our sample group by using questionnaire survey methods and studied the mechanism of innovative behavior driven by engineers' individual continuous learning through statistical analysis, which indicated that the engineers who engage in individual continuous learning experience an increase in innovative behavior. Risk tolerance, career planning, and organizational climate were also shown to have impacts on the process of innovative behavior. The results of this study are not only helpful for enriching the theory behind engineer vocational education from the self-determination perspective but are also helpful for improving the grassroots innovation. The findings of this study can be used not only for individual career planning and innovation management but also for organizational innovation management and engineer management. When engineers make full use of their potential personal abilities, they will be able to stimulate their internal motivation for self-growth and innovation. If organizations have a clearer understanding of engineers' abilities, they can identify the effective path of innovative behavior from the perspective of engineers' self-determination, which will be helpful for improving the effects of innovation and engineers' management and education.

\section{Literature Review and Research Hypothesis}

According to the planned behavior theory, there are five core elements in the planned behavior theory, including attitude, subjective norm, perceived behavioral control, behavioral intention, and 
behavior [9]. Attitudes, subjective norms, and perceived behavioral control not only positively affect behavioral intention but also share common beliefs [9]. Moreover, scholars used the planned behavior theory to study people's innovative behavior [10]. To apply the theory of planned behavior theory in our study, we chose continuous learning as the perceived behavioral control of innovative behavior, career planning as the behavioral intention, self-efficacy and risk tolerance as attitudes affecting engineers' innovative behavior, the organizational climate as the perceived subjective norm, and engineers' innovative behavior as the practical action so as to explore the mechanism of five factors on the engineers' innovative behavior.

In addition, engineers are able to choose their actions on the basis of fully understanding their personal needs and environmental information, which is not only the reflection of the self-role expectation emphasized by self-determination theory but also the engineers' common belief in the planned behavior theory. Therefore, engineers are able to choose their behavior according to the changes in the internal and external environment of the organization, which are not only connections of the planned behavior theory and self-determination theory but are also the starting point of our research on engineers' bottom-up innovation. On the basis of the planned behavior theory, we constructed a theoretical framework, describing the mechanisms of individual continuous learning on engineers' innovative behavior, and self-determination runs through the whole process of behavior. According to the theory of planned behavior, individual continuous learning may influence innovative behavior through the mediating role of self-efficacy and career planning. Risk tolerance and the organizational climate may also influence the above relationships.

\subsection{Individual Continuous Learning Effect on Engineers' Innovative Behavior}

Individual continuous learning focuses on the personal level, which is different from the continuous learning containing levels of individual, group, team, and organization. Individual continuous learning mainly refers to the individual's initiative learning behavior based on their perception and demand, which contains three aspects, including the individual's willingness, ability, and free choice for learning methods [11,12]. As the perceived behavioral control, individual continuous learning can directly affect employees' innovative behaviors [9]. Change needs to incorporate new technologies, methods or ideas in the current state. In order to achieve the goal of innovation, engineers need to constantly learn and absorb external information. In the process of continuous learning, the development of knowledge and skills acquired by engineers can affect their creativity as employees [13]. In addition, learning from suppliers is an effective and inexpensive way to do this [3]. By accurately configuring and integrating engineers' knowledge, small and medium-sized enterprises (SMEs) can continuously meet the needs of innovative manufacturing or delivery processes with the help of engineers, thus bringing about innovation [14].Therefore, we propose the following hypothesis:

Hypothesis 1. Engineers' individual continuous learning positively promotes innovative behavior.

\subsection{Self-Efficacy's Effect on Individual Continuous Learning and Engineers' Innovative Behavior}

Based on the theory of planned behavior, the perceived behavioral control can influence behavioral attitude [15]. In the self-determination theory, behavioral attitude, as an individual's response to his/her expected behavior, will have important impacts on practical action [16]. For innovative actors, new technologies or methods are often used to solve existing problems in innovation. The continuous learning process of these actors is a dynamic decision-making process, and social learning is the decisive factor affecting technology adoption [14]. However, due to the complexity and difficulty of the target objects, the learning ability of the actors affects their perceptions of market changes and their acceptance of new technologies [17]. Self-efficacy represents engineers' perception and judgment of their own specialty, ability, and technology. When self-efficacy is high, engineers are more confident to learn to master new technologies or achieve desired goals. Especially in the process of innovation, 
there will be unexpected failures and repeated attempts. Therefore, when engineers are more confident in their own professions and abilities, they may achieve exploitative or explorative innovation through accumulated experience or skills. Therefore, we propose the following hypothesis:

Hypothesis 2. Self-Efficacy plays a mediating role between engineers' individual continuous learning and innovative behavior.

\subsection{Career Planning's Effect on Individual Continuous Learning and Engineers' Innovative Behavior}

According to the theory of planned behavior, perceived behavioral control can also indirectly influence practical action through behavioral intention [15]. Participation in various learning and exchange activities inside and outside the organization by professionals promotes the acquisition of the latest skills and knowledge [11]. Organizations should protect engineers' learning time and provide organizational support so that they can ultimately promote professional development through critical thinking [18]. An important aspect of the connotation of continuous learning is to maintain the sustainable development of professional competence [11]. There is an important relationship between personal professional development and career aspirations, which can be achieved through professional learning plans and a series of activities [6]. At the same time, career-related continuous learning can help organizational members meet their psychological needs and realize their intrinsic value, thus gaining a competitive advantage in the job market [19].

Furthermore, according to the self-determination theory, engineers should be able to design their career orientation according to personal experience, information, and their surrounding environment. If personal career planning is consistent with organizational innovation, individuals and organizations will form a more cohesive bond [20]. Once the occupation is positioned as a work goal, technical personnel will be more active in innovative behavior [21]. Career planning ability is beneficial to personal innovative behavior [20]. In view of this, we propose the following hypothesis:

Hypothesis 3. Engineers' career planning positively affects their innovative behavior.

\subsection{Risk Tolerance's Effect on Individual Continuous Learning and Self-Efficacy}

Behavioral attitudes and perceived behavioral control are conceptually distinct but sometimes share common beliefs, so they are both independent and related to each other $[9,15]$. Professionals in the organization need to master relevant knowledge, skills, and abilities in carrying out tasks related to the work or discipline [11]. In addition to education and training, professionals gain new skills through on-the-job experience, involving their own or others' experience [11]. Organizations face risks in project evaluation when information is incomplete and vague, and the biggest obstacles lie in the lack of organizational learning and resistance to change [22]. Learning is a continuous process and part of organizational change, and individuals continue to learn in order to reduce risk factors [22]. If an engineer is more risk-tolerant, he/she will be less afraid of the difficulties or possible failures of exploring new knowledge or skills. With the support of supervisors, training is an important way to transfer skills to the workplace and plays a positive role [23]. In view of this, we propose the following hypothesis:

Hypothesis 4. Risk tolerance positively moderates the effect of individual continuous learning on self-efficiency.

\subsection{Organizational Climate's Effect on the Mediation Model}

According to the self-determination theory, engineers have the ability to perceive the information and environment around them [16]. We regarded the organizational climate as the subjective norm 
of innovative behavior, reflecting the possible impact of the environment perceived by engineers on innovative behavior. Morland found that there are four levels of continuous learning: individual, team, region, and organization [21]. Time, communication, and trust within the organization are not only interrelated but also affect the causes of continuous learning and cross-level learning [21]. When engineers continue to keep learning according to their job requirements, sometimes, they need to spend money on learning. When organizations are unwilling to support engineers financially, they probably give up learning opportunities because of the financial burden. In addition, in the context of a Chinese work environment, engineers are influenced by the values of collectivist culture, and most engineers tend to follow the trend. Therefore, when engineers feel that the organizational climate is not conducive to personal innovation, although they have the ability to achieve creative ideas, engineers will also reveal their ideas about personal career planning, or even conceal their talents, in order to avoid making themselves into a "stand out" situation in the organization [20]. Therefore, based on the above analysis, we proposed the following two hypotheses:

Hypothesis 5. An organizational climate positively influences the indirect effect of engineers' individual continuous learning on innovative behavior through career planning, and the more favorable an organizational climate is, the stronger the indirect effect.

Hypothesis 6. An organizational climate positively influences the indirect effect of engineers' individual continuous learning on innovative behavior through self-efficacy, and the more favorable an organizational climate is, the stronger the indirect effect (see Figure 1).

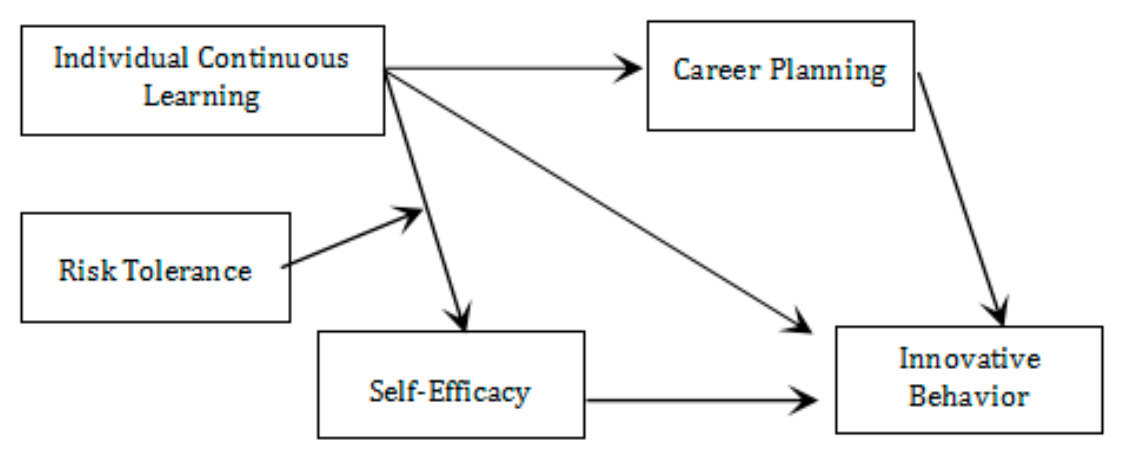

Figure 1. Research structure model.

\section{Research Methodology}

\subsection{Sampling and Data Collection}

This study focused on the mechanisms of engineers' individual continuous learning on innovative behavior. Therefore, we chose middle-level and grassroots engineers who were engaged in engineering or technical posts in mainland China as the respondents. From September 2017 to March 2018, we conducted a formal questionnaire survey through online and on-site channels in mainland China. Ultimately, we obtained 292 valid questionnaires and used SPSS 19.0 and Process to analyze the data and test the hypothesis. The sample was comprised of 292 engineers from various industries (medical treatment, real estate, communications electronics, retail, finance, service, manufacturing, public affairs, etc.), all of which aimed to represent engineers from the Chinese labor market. Of the respondents, 177 were males and 115 were females, accounting for $60.6 \%$ and $39.4 \%$, respectively. The age of the interviewees ranged from 21 to 60 years of age. More than $50 \%$ of the respondents have undergraduate and above degrees. More than $50 \%$ of the respondents have job tenure ranging from 1 to 2 years. As for organization size, organizations of $10-49$ people accounted for $25.3 \%$, 50-99 people accounted for $12 \%$, 
100-149 people accounted for $14.9 \%, 150-199$ people accounted for $9.9 \%, 200-499$ people accounted for $8.2 \%$, and more than 500 people accounted for $29.8 \%$.

\subsection{Variable Measurement}

The constructs used in this study were measured with maturity scales. Individual continuous learning, career planning and risk tolerance were measured by scales adopted by M. Wang and Li [12] and Liu et al. [11]. Engineers' innovative behavior was measured with the Employee Innovative Behavior Scale developed by Scott and Bruce [24], which was used in many research fields to reflect employees' innovative behavior, such as knowledge workers. What is more, engineers are also knowledge workers, so we use this scale to measure the innovative behavior of engineers. The organizational climate was measured by the six-item organizational climate scale developed by Li [25] on the basis of the research of Amiable et al. [26] and S. Wang et al. [27] The organizational climate was measured from three perspectives of leadership support, colleague support and organizational system combined with the Chinese situation. What is more, on the basis of the 10 level self-efficacy scale developed by Riggs [28], Feng et al. [29] deleted five items and revised some inverse items to measure self-efficacy from the perspectives of personal ability, skills, and confidence. In view of the fact that the scale was developed by Feng et al. [29], it is widely used in the Chinese context. Therefore, we also used the revised scale to measure self-efficacy. In addition, through literature review, we found that genders, ages, industries, and other factors might also have impacts on the results, so we used them as the control variable in this study in order to accurately reflect the relationship between variables.

\section{Data analysis}

\subsection{Reliability and Validity Analysis}

Through the correlation analysis of variables, it was found that six factors-individual continuous learning, self-efficacy, organizational climate, innovation, risk tolerance, and career planning-are correlated with each other and their correlation coefficients are between 0.230 and 0.633 , which mean that the relationships between variables should be further explored (see Table 1).

Convergent Validity (CV) reflects whether each index reflects the same concept. It is generally measured by Confirmatory Factor Analysis (CFA) and Average Variance Extracted (AVE). In this study, Mplus 6.12 and SPSS 19.0 software were used to carry out the CFA. The results show that the standardized factor loading coefficients of 27 measurement items are all greater than 0.5 . In addition, the AVE values of the six factors are all higher than the threshold value of 0.5 , indicating that the questionnaire has good convergence validity. The combined reliability $(\mathrm{CR})$ values of the six dimensions are all greater than 0.6 (see Table 2). The scales used in this study are all from mature scales adopted by scholars, which infers that the content reliability of the scales is good. Correlation coefficients between variables were calculated to determine the level of multiple co-linearity. It was found that the correlation coefficients between the six dimensions were less than 0.7 (see Table 1), indicating that the scales had good discriminatory validity. Furthermore, the square roots of the AVE values of the six factors are greater than the absolute values of the correlation coefficients [30], which indicates that the scale has good discriminatory validity. 
Table 1. Correlation analysis.

\begin{tabular}{|c|c|c|c|c|c|c|c|c|c|c|c|c|c|}
\hline & Mean & SD & 1. & 2. & 3. & 4. & 5. & 6. & 7. & 8. & 9. & 10. & 11. \\
\hline 1. Gender & 1.61 & 0.489 & 1 & & & & & & & & & & \\
\hline 2. Age & 2.48 & 1.545 & 0.049 & 1 & & & & & & & & & \\
\hline 3. Organization size & 3.53 & 1.994 & 0.028 & $0.173^{* *}$ & 1 & & & & & & & & \\
\hline 4. Education & 2.70 & 1.031 & -0.036 & $0.530 * *$ & $0.271 * *$ & 1 & & & & & & & \\
\hline 5. Job tenure & 2.04 & 1.254 & $0.116^{*}$ & $0.793^{* *}$ & 0.210 ** & $0.557^{* *}$ & 1 & & & & & & \\
\hline $\begin{array}{l}\text { 6. Individual continuous } \\
\text { learning }\end{array}$ & 4.060 & 0.810 & 0.000 & 0.148 * & -0.075 & -0.037 & 0.037 & 1 & & & & & \\
\hline 7. Self-efficacy & 3.480 & 0.829 & -0.054 & $0.211^{* *}$ & 0.003 & 0.102 & $0.156^{* *}$ & $0.525^{* *}$ & 1 & & & & \\
\hline 8. Organizational climate & 3.962 & 0.847 & 0.012 & $-0.249^{* *}$ & -0.090 & $-0.495^{* *}$ & $-0.295^{* *}$ & $0.298 * *$ & $0.230^{* *}$ & 1 & & & \\
\hline 9. Innovation & 3.527 & 0.909 & -0.061 & 0.070 & -0.045 & -0.060 & 0.008 & $0.556 * *$ & $0.585^{* *}$ & $0.435^{* *}$ & 1 & & \\
\hline 10. Risk tolerance & 3.430 & 0.970 & -0.093 & -0.094 & $-0.217^{* *}$ & $-0.263 * *$ & $-0.190 * *$ & $0.403 * *$ & $0.315^{* *}$ & $0.374^{* *}$ & $0.493^{* *}$ & 1 & \\
\hline 11. Career planning & 3.682 & 0.962 & -0.016 & $0.118 *$ & $-0.115 *$ & -0.105 & -0.021 & 0.633 ** & $0.478^{* *}$ & $0.414 * *$ & $0.604^{* *}$ & $0.461 * *$ & 1 \\
\hline
\end{tabular}


Table 2. Results of the confirmatory factor analysis.

\begin{tabular}{|c|c|c|c|c|c|}
\hline Factor & Item & $\begin{array}{c}\text { Factor } \\
\text { Loading }\end{array}$ & AVE & CR & Reference \\
\hline Risk tolerance & $\begin{array}{c}\text { I am willing to take all kinds of risks on my own initiative. } \\
\text { Faced with difficulties, I like to try bold plans. } \\
\text { I prefer adventure. }\end{array}$ & $\begin{array}{l}0.728 \\
0.880 \\
0.744\end{array}$ & 0.6193 & 0.8289 & $\begin{array}{l}\text { M. Wang and Li (2011) } \\
\text { and Liu et al. (2019) }\end{array}$ \\
\hline Continuous learning & $\begin{array}{l}\text { I can update my skills and knowledge quickly according } \\
\text { to the changes of the organization. } \\
\text { If I know what I need to learn, I will actively seek } \\
\text { learning opportunities. } \\
\text { I often read, discuss or attend meetings to understand the } \\
\text { trend of development in my field. }\end{array}$ & $\begin{array}{l}0.692 \\
0.777 \\
0.746\end{array}$ & 0.5464 & 0.7829 & $\begin{array}{l}\text { M. Wang and Li (2011) } \\
\text { and Liu et al. (2019) }\end{array}$ \\
\hline Organizational climate & $\begin{array}{c}\text { Colleagues can support and assist each other } \\
\text { Colleagues are willing to share their views } \\
\text { My supervisor encourages his subordinates to express } \\
\text { their new ideas. } \\
\text { There are no communication barriers within the } \\
\text { organization } \\
\text { The performance evaluation system of my organization is } \\
\text { fair and reasonable } \\
\text { My supervisor treats his colleagues equally. }\end{array}$ & $\begin{array}{l}0.630 \\
0.707 \\
0.731 \\
\\
0.722 \\
0.780 \\
0.760\end{array}$ & 0.5231 & 0.8676 & $\begin{array}{l}\mathrm{Li}(2016) \text {, Amabile et } \\
\text { al. (1996) and S. Wang } \\
\quad \text { et al. (2013) }\end{array}$ \\
\hline Personal efficacy & $\begin{array}{l}\text { I have confidence in my ability to do my job. } \\
\text { I have all the skills needed to perform my job very well. } \\
\text { I am an expert at my job. } \\
\text { I am very proud of my job skills and abilities. } \\
\text { I have all the professional knowledge of the position I am } \\
\text { engaged in. }\end{array}$ & $\begin{array}{l}0.600 \\
0.632 \\
0.813 \\
0.752 \\
0.771\end{array}$ & 0.5161 & 0.8403 & $\begin{array}{l}\text { Riggs et al. (1994), } \\
\text { Feng et al. (2009) }\end{array}$ \\
\hline Innovative behavior & $\begin{array}{c}\text { I often search out new technologies, processes, } \\
\text { techniques, and/or product ideas. } \\
\text { I often generate creative ideas } \\
\text { I often promote and champion ideas to others. } \\
\text { I often investigate and secure funds needed to implement } \\
\text { new ideas. } \\
\text { I often develop adequate plans and schedules for the } \\
\text { implementation of new ideas. } \\
\text { I am innovative. }\end{array}$ & $\begin{array}{l}0.738 \\
0.753 \\
0.773 \\
0.814 \\
\\
0.723 \\
0.760\end{array}$ & 0.5787 & 0.8916 & Scott and Bruce (1994) \\
\hline Career planning & $\begin{array}{l}\text { I can adjust my career goals according to the changes in } \\
\text { the strategy and structure of the company. } \\
\text { I can set difficult but not impossible career goals. } \\
\text { I have a clear plan for my career development. } \\
\text { I have worked out a practical career development plan } \\
\text { and made great efforts for it. }\end{array}$ & $\begin{array}{l}0.902 \\
0.893 \\
0.550 \\
0.561\end{array}$ & 0.5571 & 0.8266 & $\begin{array}{l}\text { M. Wang and } \operatorname{Li}(2011) \\
\text { and Liu et al. (2019) }\end{array}$ \\
\hline
\end{tabular}

\subsection{Test Steps and Principles}

The organizational climate is one of the main constructs in our study, and there may be significant differences in organizational climates among different industries. Therefore, we used dummy variables to further analyze whether different industries have impacts on engineers' innovative behavior. The communications electronics industry is one of the representative industries in the engineering field, and, compared with the other engineering industries in our study, it has, relatively speaking, more samples. So, we used it as a reference group to observe the changes in other industries.

Firstly, we used multiple linear regression analysis to testify the effect of individual continuous learning on engineers' innovative behavior. Table 3 shows that the regression equation $R^{2}$ passes the significance test. The standardized regression coefficient of individual continuous learning on engineers' innovative behavior is 0.549 , and the confidence interval is [0.503, 0.729] (see Table 3). These metrics show that individual continuous learning significantly promotes engineers' innovative behavior. Consequently, Hypothesis $\mathrm{H} 1$ is supported

Secondly, we constructed a dual mediation model to test the mediating effects of individual continuous learning and self-efficacy by using the SPSS Process Procedure, which included the direct effect of individual continuous learning on engineers' innovative behavior. The model's $R^{2}$ is 0.5137 , $\mathrm{F}=18.1577(p<0.001)$, so the statistical fit of the model meets the requirements (see Table 4$)$. The total indirect effect of individual continuous learning on engineers' innovative behavior includes two paths. The path coefficient of individual continuous learning $\rightarrow$ self-efficacy $\rightarrow$ engineers' innovative behavior is 0.2017 , and that of individual continuous learning $\rightarrow$ career planning $\rightarrow$ engineers' innovative behavior is 0.2253 . Their indirect effects confidence intervals do not include 0 , indicating that career planning and self-efficacy play a mediating role at the same time. After adding two mediating variables, the 
regression coefficient of individual continuous learning $\rightarrow$ innovative behavior is 0.1889 , which is lower than that before $(0.1889<0.549)$, indicating that individual continuous learning and self-efficacy play partial intermediary roles. However, in the path $(\mathrm{CL} \rightarrow \mathrm{CP})$ of the dual mediation mode, the age, a control variable, passes the significance test $(\beta=0.1187, p<0.05)$, indicating that the age has impacts on the relationship of engineers' individual continuous learning to career planning (see Table 4 ). What is more, the regression coefficients of industries in this model are not significant. Therefore, Hypothesis $\mathrm{H} 2$ and Hypothesis $\mathrm{H} 3$ are validated.

Table 3. Regression analysis of the impact of individual continuous learning on innovative behavior.

\begin{tabular}{|c|c|c|c|c|c|c|c|c|}
\hline \multirow{2}{*}{ Model } & \multirow{2}{*}{ SD } & \multirow{2}{*}{$\begin{array}{l}\text { Standard } \\
\text { Coefficient }\end{array}$} & \multirow{2}{*}{$\mathbf{t}$} & \multicolumn{2}{|c|}{$95.0 \%$ CI } & \multirow{2}{*}{$\mathbf{R}^{2}$} & \multirow{2}{*}{$\operatorname{Adj} R^{2}$} & \multirow{2}{*}{$\mathbf{F}$} \\
\hline & & & & Lower & Upper & & & \\
\hline $\begin{array}{l}\text { Individual } \\
\text { continuous } \\
\text { learning }\end{array}$ & 0.058 & $0.549^{* * *}$ & 10.697 & 0.503 & 0.729 & \multirow{14}{*}{0.333} & \multirow{14}{*}{0.299} & \multirow{14}{*}{$9.874^{* * *}$} \\
\hline Gender & 0.096 & -0.078 & -1.517 & -0.333 & 0.043 & & & \\
\hline Age & 0.052 & -0.003 & -0.035 & -0.104 & 0.100 & & & \\
\hline $\begin{array}{l}\text { Organization } \\
\text { size }\end{array}$ & 0.024 & -0.018 & -0.339 & -0.056 & 0.040 & & & \\
\hline Education & 0.062 & -0.013 & -0.179 & -0.132 & 0.110 & & & \\
\hline Job tenure & 0.064 & 0.026 & 0.290 & -0.108 & 0.145 & & & \\
\hline Health care & 0.381 & 0.040 & 0.734 & -0.471 & 1.031 & & & \\
\hline Real estate & 0.300 & -0.102 & -1.789 & -1.126 & 0.054 & & & \\
\hline Retail & 0.570 & 0.006 & 0.122 & -1.052 & 1.191 & & & \\
\hline Finance & 0.179 & -0.054 & -0.642 & -0.466 & 0.237 & & & \\
\hline Services & 0.180 & -0.047 & -0.593 & -0.461 & 0.248 & & & \\
\hline Manufacturing & 0.303 & 0.046 & 0.801 & -0.354 & 0.839 & & & \\
\hline Public affairs & 0.231 & -0.091 & -1.195 & -0.731 & 0.179 & & & \\
\hline Others & 0.193 & -0.087 & -0.906 & -0.555 & 0.205 & & & \\
\hline
\end{tabular}

Notes: ${ }^{* * *} p<0.001$. Dependent variable: innovative behavior.

Table 4. Regression results of the dual mediation model.

\begin{tabular}{cccc}
\hline \multirow{2}{*}{ Predictive Variables } & \multicolumn{3}{c}{ Dependent Variable } \\
\cline { 2 - 4 } & Career & Self-Efficacy & Innovative Behavior Model 4 \\
\hline Constant & $1.1065^{* *}$ & $1.4657^{* * * *}$ & 0.5026 \\
Gender & -0.0238 & -0.1355 & -0.0858 \\
Age & $0.1187^{*}$ & 0.0027 & -0.0407 \\
Organization size & -0.0307 & 0.0032 & 0.0003 \\
Education & -0.0728 & 0.0224 & 0.0036 \\
Job tenure & -0.0904 & 0.0401 & 0.0321 \\
Health care & -0.1540 & 0.5394 & 0.1234 \\
Real estate & -0.0569 & -0.0420 & -0.5020 \\
Retail & 0.2112 & 0.5048 & -0.1901 \\
Finance & -0.0504 & -0.2397 & -0.0073 \\
Services & -0.0378 & -0.1762 & -0.0276 \\
Manufacturing & 0.3418 & 0.1384 & 0.0810 \\
Public affairs & 0.0164 & -0.0631 & -0.2571 \\
Others & -0.1733 & 0.0161 & -0.1258 \\
Individual continuous & $0.7066^{* * *}$ & $0.5293 * * *$ & $0.1889 * *$ \\
learning & & & $0.3811^{* * *}$ \\
Self-efficacy & & & $0.3189^{* * *}$ \\
Career planning & $15.1413^{* * *}$ & $9.6758^{* * *}$ & $18.1577^{* * *}$ \\
F & 0.6584 & 0.5731 & 0.7167 \\
R & &
\end{tabular}

Notes: ${ }^{*} p<0.05,{ }^{* *} p<0.01,{ }^{* * *} p<0.001 . \mathrm{N}=292$. 
Thirdly, according to the moderating effect method designed by Wen et al. [31], we validated the moderating effect of risk tolerance by using a hierarchical regression method. The results are shown in Table 5. With self-efficacy as the dependent variable, the control variables and individual continuous learning were analyzed in Model 1 (see Table 5). The results show that age has a significant impact on self-efficacy. Model 2 was formed by adding individual continuous learning variables into Model 1. The F value of Model 2 is $9.676(p<0.001)$ and $\Delta R^{2}$ is 0.245 , which indicates that individual continuous learning can explain $24.5 \%$ of the variation changes in self-efficacy. On the basis of Model 2, risk tolerance variables were added to Model 3. The F value of Model 3 is $10.017(p<0.001)$ and $\Delta R^{2}$ is 0.024 , indicating that risk tolerance together can explain $2.4 \%$ of the variation change in self-efficacy. Based on Model 3, individual continuous learning and risk tolerance interaction items were added to Model 4. The F value of Model 4 is $9.840(p<0.001)$ and $\Delta R^{2}$ is 0.012 , indicating that the model passes the test of significance and can explain $1.2 \%$ of the variation changes in self-efficacy. The regression coefficient of the interaction between individual continuous learning and risk tolerance is $0.768(p<0.05)$, which indicates that risk tolerance has a significant positive effect on the relationship between individual continuous learning and self-efficacy. Therefore, Hypothesis H4 is validated.

Table 5. The moderating effect of risk tolerance.

\begin{tabular}{|c|c|c|c|c|}
\hline \multirow{2}{*}{$\begin{array}{l}\text { Independent } \\
\text { Variables }\end{array}$} & \multicolumn{4}{|c|}{ Dependent Variable: Self-Efficacy } \\
\hline & Model 1 & Model 2 & Model 3 & Model 4 \\
\hline Gender & -0.081 & -0.080 & -0.067 & -0.066 \\
\hline Age & 0.191 & 0.005 & -0.011 & -0.005 \\
\hline Organization size & -0.036 & 0.008 & 0.031 & 0.031 \\
\hline Education & 0.017 & 0.028 & 0.061 & 0.081 \\
\hline Job tenure & 0.002 & 0.061 & 0.083 & 0.063 \\
\hline Health care & 0.061 & 0.085 & 0.084 & 0.096 \\
\hline Real estate & -0.002 & -0.009 & -0.020 & -0.010 \\
\hline Retail & 0.066 & 0.050 & 0.052 & 0.047 \\
\hline Finance & -0.172 & -0.123 & -0.125 & -0.104 \\
\hline Services & -0.138 & -0.085 & -0.076 & -0.070 \\
\hline Manufacturing & 0.001 & 0.029 & 0.028 & 0.037 \\
\hline Public affairs & -0.117 & -0.023 & -0.022 & -0.018 \\
\hline Others & -0.124 & 0.009 & 0.016 & 0.030 \\
\hline $\begin{array}{l}\text { Individual } \\
\text { continuous } \\
\text { learning }\end{array}$ & & $0.517^{* * *}$ & $0.450^{* * *}$ & 0.089 \\
\hline Risk tolerance & & & $0.181^{* *}$ & -0.357 \\
\hline $\begin{array}{c}\text { Individual } \\
\text { continuous } \\
\text { learning * Risk } \\
\text { tolerance tolerance }\end{array}$ & & & & $0.768 *$ \\
\hline $\mathrm{F}$ & $1.954 *$ & $9.676^{* * *}$ & $10.017^{* * *}$ & $9.840^{* * *}$ \\
\hline$\Delta \mathrm{F}$ & 1.954 * & $100.922 * * *$ & $10.261^{* *}$ & $5.005^{*}$ \\
\hline $\mathrm{R}^{2}$ & 0.084 & 0.328 & 0.352 & 0.364 \\
\hline$\Delta \mathrm{R}^{2}$ & 0.084 & 0.245 & 0.024 & 0.012 \\
\hline
\end{tabular}

Notes: ${ }^{*} p<0.05,{ }^{* *} p<0.01,{ }^{* * *} p<0.001 . \mathrm{N}=292$.

Fourthly, we used Wen's methods to testify whether the organizational climate plays a moderating role in the mediating effect [32]. According to the procedure designed by Wen [32], we tested the impact of the organizational climate on the mediating effect, taking career planning as the mediator. When tested models meet the following four conditions, it means the moderator affects the dependent variable through independent variables. The steps are as follows: (1) Make the regression of engineers' innovative behavior to individual continuous learning and organizational climate, and test whether individual continuous learning has significant impacts on engineers' innovative behavior. (2) Make 
the regression of career planning to individual continuous learning and organizational climate, and test whether individual continuous learning has significant impacts on career planning. (3) Make the regression of engineers' innovative behavior to individual continuous learning, the organizational climate, and career planning, and test whether the mediating effect of career planning is significant between individual continuous learning and innovative behavior. (4) Make the regression of engineers' innovative behavior to individual continuous learning, career planning, the organizational climate, and the interaction between the organizational climate and career planning, and test whether the effect of the interaction between the organizational climate and career planning is significant.

The models corresponding to the above four steps are shown in Table 6, Model 2, Model 5, Model 3, and Model 4. The results are as follows: (1) Model 2 shows that individual continuous learning significantly affects engineers' innovative behavior $(\beta=0.492, p<0.001)$; (2) Model 5 shows that individual continuous learning significantly affects career planning $(\beta=0.607, p<0.001)$; (3) Model 3 shows that career planning plays a significant mediating role in the relationship between individual continuous learning and innovative behavior ( $\beta=0.317, p<0.001)$; (4) Model 4 shows that the interaction term between the organizational climate and career planning passes the significance test $(\beta=0.100, p<0.05)$.

Table 6. Moderating effect of the organizational climate on the mediating effect.

\begin{tabular}{|c|c|c|c|c|c|c|c|c|}
\hline \multirow{2}{*}{$\begin{array}{l}\text { Independent } \\
\text { Variables }\end{array}$} & \multicolumn{4}{|c|}{ IB } & \multirow{2}{*}{$\frac{\text { CP }}{\text { Model } 5}$} & \multicolumn{2}{|c|}{ IB } & \multirow{2}{*}{$\frac{\text { SE }}{\text { Model } 8}$} \\
\hline & Model 1 & Model 2 & Model 3 & Model 4 & & Model 6 & Model 7 & \\
\hline Constant & $3.994 * * *$ & -0.112 & -0.072 & 1.285 & -0.127 & -0.357 & 0.597 & 0.626 \\
\hline Gender & -0.148 & -0.145 & -0.137 & -0.126 & -0.024 & -0.092 & -0.096 & -0.135 \\
\hline Age & 0.114 & 0.005 & -0.035 & -0.041 & 0.124 * & 0.002 & 0.001 & 0.006 \\
\hline Organization size & -0.029 & -0.018 & -0.006 & -0.010 & -0.039 & -0.017 & -0.017 & -0.002 \\
\hline Education & -0.021 & 0.136 * & $0.121 *$ & 0.125 * & 0.046 & 0.095 & 0.100 & 0.103 \\
\hline Job tenure & -0.026 & 0.018 & 0.047 & 0.054 & -0.091 & 0.003 & 0.004 & 0.040 \\
\hline Health care & 0.108 & 0.582 & 0.553 & 0.553 & 0.090 & 0.306 & 0.365 & 0.706 * \\
\hline Real estate & -0.496 & -0.371 & -0.396 & -0.343 & 0.076 & -0.390 & -0.370 & 0.049 \\
\hline Retail & 0.249 & 0.074 & 0.006 & -0.033 & 0.215 & -0.124 & -0.167 & 0.507 \\
\hline Finance & -0.225 & -0.123 & -0.105 & -0.088 & -0.057 & -0.027 & -0.022 & -0.244 \\
\hline Services & -0.234 & -0.099 & -0.089 & -0.088 & -0.032 & -0.032 & -0.043 & -0.172 \\
\hline Manufacturing & 0.087 & 0.259 & 0.147 & 0.110 & 0.355 & 0.201 & 0.160 & 0.147 \\
\hline Public affairs & $-0.579 *$ & -0.195 & -0.221 & -0.202 & 0.082 & -0.188 & -0.195 & -0.018 \\
\hline Others & $-0.458 *$ & -0.129 & -0.086 & -0.062 & -0.136 & -0.145 & -0.141 & 0.041 \\
\hline CL & & $0.492^{* * *}$ & $0.300^{* * *}$ & 0.283 & $0.607^{* * *}$ & $0.312^{* * *}$ & $0.312^{* * *}$ & $0.461^{* * *}$ \\
\hline $\mathrm{OC}$ & & $0.409^{* * *}$ & $0.304^{* * *}$ & -0.033 & $0.330^{* * *}$ & $0.321^{* * *}$ & 0.083 & $0.225^{* * *}$ \\
\hline $\mathrm{CP}$ & & & $0.317^{* * *}$ & -0.083 & & & 0.100 & \\
\hline $\mathrm{CP}^{*} \mathrm{OC}$ & & & & 0.100 * & & & 0.071 & \\
\hline SE & & & & & & $0.391^{* * *}$ & 0.100 & \\
\hline $\mathrm{SE}^{*} \mathrm{OC}$ & & & & & & & 0.071 & \\
\hline$\Delta \mathrm{F}$ & 1.301 & $89.070 * * *$ & $30.621^{* * *}$ & $4.270 *$ & $17.574^{* * *}$ & $45.292 * * *$ & 1.895 & $10.472 * * *$ \\
\hline $\mathrm{R}^{2}$ & 0.057 & 0.427 & 0.485 & 0.492 & 0.489 & 0.508 & 0.512 & 0.363 \\
\hline$\Delta \mathrm{R}^{2}$ & 0.057 & 0.370 & 0.057 & 0.008 & 0.489 & 0.081 & 0.003 & 0.363 \\
\hline
\end{tabular}

Notes: ${ }^{*} p<0.05,{ }^{* * *} p<0.001$. $\mathrm{N}=292$. OC: organization climate, CP: career planning, SE: self-efficacy, CL: individual continuous learning, IB: innovative behavior.

We found that the organizational climate plays a moderating role in the model with career planning as the mediator. However, we need to further explore whether there are significant differences in the mediating role of career planning in different organizational climates. So, we used the Mplus 6.12 to calculate their effects. We chose the variables of the organizational climate and divided them into two groups according to scores (mean value $\pm \mathrm{SD}$ ): signifying a high and low organizational climate. Table 7 shows that in the high score group, the path coefficient of individual continuous learning $\rightarrow$ career planning $\rightarrow$ innovative behavior is 0.407 , and the confidence interval is $[0.278,0.564]$. That is higher than the path coefficient in the low score group, which is 0.300 , and its confidence interval is [0.171, 0.444] (see Table 7). The conclusion also verified the moderating effect of the organizational climate on the mediating effect. Moreover, the difference between the two groups is significant ( $\beta=0.107, \mathrm{CI}[0.009$, $0.218]$ ), indicating that the more favorable the organizational climate, the stronger the mediating effect 
of career planning. After adding the organizational climate into models, both education and medical treatment have impacts on innovative behavior in Model 2 and Model 3. And in Model 4, education has a positive impact on innovative behavior.

Table 7. Mediating effects of career planning on different levels of the organizational climate.

\begin{tabular}{ccc}
\hline Moderator Variable & Point Estimate & 95\% CI \\
\hline High organizational climate & $0.407^{* *}$ & {$[0.278,0.564]$} \\
Low organizational climate & $0.300^{* *}$ & {$[0.171,0.444]$} \\
Difference & $0.107^{*}$ & {$[0.009,0.218]$} \\
\hline
\end{tabular}

Notes: ${ }^{*} p<0.05,{ }^{* *} p<0.01,95 \% \mathrm{CI}, 5000$ Bootstrap.

Using the same method, we tested the influence of the organizational climate on the mediating effect, with self-efficacy as the mediator. The results are shown in Table 6, Model 6, Model 8, and Model 7. Model 7 shows that $S E^{*} \mathrm{OC}$ does not pass the significance test $(\beta=0.071, p>0.05)$, illustrating that the organizational climate does not moderate the mediating effect. Therefore, Hypothesis 6 is not supported.

Table 6 shows that there may be differences in the organizational climates among different industries. So, we used one-way ANOVA to test this. We chose Tamhane's T2 and Dunnett's methods without assuming homogeneity of variances. The value of the Welch test is $6.142(p<0.01)$, and the value of the Brown-Forsythe test is $5.989(p<0.001)$, indicating there are significant differences between industries.

\section{Result}

Using the theory of planned behavior as its basis, this paper studied the mechanism of engineers' innovative behavior under the influence of risk tolerance, career planning, self-efficacy, and organizational climate, with individual continuous learning as the independent variable, and drew the following conclusions:

Firstly, facing difficulties or task requirements in innovation, engineers' individual continuous learning promotes innovative behavior. Engineers need to integrate resources and information continuously according to the innovation aims of their organization. With a deeper integration of technology and organization, engineers must lead or adapt to organizational changes by updating their knowledge and skills so as to contribute to support organizational innovation.

Secondly, career planning and self-efficacy both mediate the relationship between engineers' individual continuous learning and innovative behavior. Self-efficacy means that the engineer has confidence in his profession and skills. After engineers acquire the knowledge or skills needed, their competence and confidence will be enhanced, which will in turn promote innovative behavior. Moreover, career planning means that the engineer has set goals for the breadth and height of their career. Through individual continuous learning, the engineer can affect their career plan. The more successful the engineer's career is, the stronger his ability to grasp the direction of work and thus promote innovative behaviors.

Thirdly, risk tolerance plays a moderating role between engineers' individual continuous learning and self-efficacy. When the engineer's risk tolerance is higher, the effect of individual continuous learning on self-efficacy is more significant. Innovation means the exploration of unknown areas and possible failure. Learning is an important way to match one's existing working ability with external resources, and learning may also face failure. When engineers risk tolerance is higher, he/she dares to break through personal bottlenecks and engages in individual continuous learning, thus increasing his self-efficacy.

Finally, the organizational climate influences the mechanism of engineers' innovative behavior as driven by individual continuous learning. When the organizational climate is more favorable, 
engineers' individual continuous learning has more significant impacts on innovative behavior through self-efficacy and career planning. However, when the engineer is in an unfavorable organizational climate, individual continuous learning can not directly promote innovative behavior. At this time, individual continuous learning needs to rely on the intermediary role of self-efficacy and career planning to promote innovative behavior.

\section{Discussion}

\subsection{Theoretical Contribution}

From a theoretical standpoint, the contributions of this study are as follows: (1) We found that individual continuous learning plays a positive role in innovative behavior and creatively studied the mechanism of grassroots innovation with engineers' individual continuous learning as the antecedent variable. (2) This research revealed the mechanism of engineers' innovative behavior, which is motivated by engineers' individual continuous learning, mediated by career planning and self-efficacy, and regulated by risk tolerance. From the subjective initiative and self-regulation ability embodied by individual engineers, it shows the possibility of innovative behavior from the bottom to the top. (3) In the context of the organizational climate, it is found that there are differences in the mechanism of engineers' innovative behavior, which is motivated by individual continuous learning and mediated by career planning and self-efficacy. From a practical standpoint, the research results verified the self-determination ability of engineers, so that engineers can stimulate individual potential in a targeted way. It can also help engineers better leverage their learning abilities, self-efficacy, risk tolerance, and career planning to optimize their innovative behavior. For organizations, they can clearly identify the effective paths of engineers' innovation and provide more accurate plans in terms of engineers' management and education so as to improve the effect of engineers' innovation, organizational management, and engineers' education.

\subsection{Implication}

This paper studied the grass-roots innovative behavior of engineers and analyzed the mechanism of the individual continuous learning of engineers on innovative behavior. The research results demonstrate that methodologies can have a positive impact on the vocational education of engineers and are significant to those involved with organizational innovation management. For engineers, they should have the spirit of lifelong learning and constantly improve their learning ability in order to improve their self-efficacy and career planning, and then promote their innovative behavior.

For organizations, improving the abilities and qualities of engineers is not only beneficial to engineers but also promotes organizational innovation. Therefore, managers and the staff of human resources departments can carry out vocational education or implement a strategic management of engineers from the following aspects. First, managers need to encourage engineers to continue learning. It is necessary to develop a continuing education plan to support engineers by providing learning opportunities and creating learning environments both inside and outside the organization. Second, the organization also needs to train engineers with new knowledge or skills so that they can enhance their competence and self-confidence through the promotion of professional skills and abilities, which, in turn, will enable them to develop their abilities and provide good psychological conditions for the better implementation of creativity. Third, managers need to pay attention to the career planning of engineers and help them achieve their career goals. Managers can conduct in-depth interviews to ascertain an engineer's career objectives, help them make career plans through systematic curriculum training, and ultimately assist them in achieving their goals. Career education for engineers is a win-win proposition for both organizations and individuals. If engineers plan their careers in a way that correlates with the future direction of the organization, it will promote long-term collaborative development between the organization and engineers. Fourth, managers also need to allow engineers to make mistakes and reduce the penalties for unintentional mistakes so that engineers are not afraid to 
take risks. At the same time, risk education for engineers should be strengthened to reduce the failure of innovation caused by moral hazard. Fifth, especially in the context of organizational specialization and elaborate management, it is very difficult for individual engineers to achieve the organizational innovation task or overall goal. Innovation goals need to be achieved by the collaborative innovation of cross-departmental teams. Therefore, managers need to create a mutually supportive and collaborative organizational innovation atmosphere to enable engineers to implement innovative behavior more effectively and achieve innovative goals. Managers need to be aware that a favorable organizational atmosphere can enhance the effect of individual continuous learning on career planning, and there are differences between the organizational atmosphere in industries.

\subsection{Limitations and Future Research}

The concepts researched herein were mainly focused on the individual and organizational factors that affect engineers' innovation. Therefore, in future research, we will comprehensively study the factors affecting the engineers' grassroots innovative behavior and their mechanisms from the perspective of teams, industries, genders, and other dimensions. In addition, the data obtained are mainly from unilateral surveys of engineers, and we have not yet used the method of paired surveys to collect questionnaires. In the future, we will use more diversified data collection methods so as to reflect the relationships between variables more comprehensively and accurately and give suggestions for engineering education. Moreover, there were differences between the organizational climates of different industries, suggesting that the relationships between the industries, organizational climates, and engineers' innovation should be further explored in the future.

Author Contributions: Funding acquisition, X.Z.; Investigation, C.Z.; Methodology, X.Z.; Resources, C.Z.; Writing-original draft, J.L. All authors have read and agreed to the published version of the manuscript.

Funding: This work was supported by (The Education Department of Henan Province in China) under Grant (2020-ZZJH-090) and (The Major humanities and Social Sciences projects of Donghua University in 2019) under Grant (108-10-0108179).

Conflicts of Interest: The authors declare no conflict of interest.

\section{References}

1. Foley, R.; Gibbs, B. Connecting engineering processes and responsible innovation: A response to macro-ethical challenges. Eng. Stud. 2019, 11, 9-33. [CrossRef]

2. Govindarajan, V.; Immelt, J.R. The only way manufacturers can survive. MIT Sloan Manag. Rev. 2019, 60. Available online: https://sloanreview.mit.edu/article/the-only-way-manufacturers-can-survive/ (accessed on 19 January 2020).

3. Linder, C. Learning from suppliers: A framework for operation innovation in small and medium sized enterprises. Prod. Plan. Control 2019, 30, 827-841. [CrossRef]

4. Wipulanusat, W.; Panuwatwanich, K.; Stewart, R.A. Pathways to workplace innovation and career satisfaction in the public service: The role of leadership and culture. Int. J. Organ. Anal. 2018, 26, 890-914. [CrossRef]

5. Fairlie, R.W.; Robb, A.M. Gender differences in business performance: Evidence from the Characteristics of Business Owners survey. Small Bus. Econ. 2009, 33, 375-395. [CrossRef]

6. Eddy, A.; Eddy, D.; Doughty, J. Evidencing continual professional development: Maximising impact and informing career planning. J. Med. Imaging Radiat. Sci. 2015, 46, 361-364. [CrossRef] [PubMed]

7. Weidekamm, C.S.; Willer, A.K. Challenges of work-life balance for women physicians/mothers working in leadership positions. Gend. Med. 2012, 9, 244-250. [CrossRef] [PubMed]

8. Siewerdsen, J.H.; Adrales, G.L.; Anderson, W.S.; Carey, J.P.; Creighton, F.X.; DiBrito, S.R.; Galaiya, D.; Marohn, M.R.; McNutt, T.R.; Osgood, G.M.; et al. Surgineering: Curriculum concept for experiential learning in upper-level biomedical engineering. Int. J. Comput. Assist. Radiol. Surg. 2019, 15, 1-14. [CrossRef] [PubMed]

9. Ajzen, I.; Fishbein, M. Factors influencing intentions and the intention-behavior relation. Hum. Relat. 1974, 27, 1-15. [CrossRef] 
10. Iglesias-Sanchez, P.P.; Jambrino-Maldonado, C.; de las Heras-Pedrosa, C. Training Entrepreneurial Competences with Open Innovation Paradigm in Higher Education. Sustainability 2019, 11, 23. [CrossRef]

11. Liu, J.; Zhao, X.; Ma, S.; Zhao, C.; Xue, F. The multi-dimensional measurement scale for knowledge employees' perception of innovation ability in China. Sci. Technol. Prog. Policy 2019, 36, 143-150.

12. Wang, M.; Li, Z. Primary development and validation of career resilience questionnaire in China. Chin. J. Clin. Psychol. 2011, 6, 730-733.

13. Zhan, X.; Yang, D.; Luan, Z.; An, Y. The relationship between proactive personality and employee creativity-The mediation effect of work engagement and personal learning. Soft Sci. 2018, 32, 82-85.

14. Genius, M.; Koundouri, P.; Nauges, C.; Tzouvelekas, V. Information transmission in irrigation technology adoption and diffusion: Social learning, extension services, and spatial effects. Am. J. Agric. Econ. 2014, 96, 328-344. [CrossRef]

15. Fishbein, M.; Ajzen, I. Belief, Attitude, Intention, and Behavior: An Introduction to Theory and Research; Addison-Wesley Publishing Company: Hoboken, NJ, USA, 1975.

16. Petri, H.L.; Govern, J.M. Motivation: Theory, Research, and Applications; Shaanxi Normal University Press: Xi'an, China, 2005.

17. Guo, G.; Lu, Q. Learning ability and external risk on farmers' adoption of water-saving irrigation techniques in Zhangye of Gansu Province. Sci. Technol. Manag. Res. 2018, 38, 229-235.

18. Brown, T.; Wassif, H.S. Understanding continuous professional development participation and choice of mid-career general dental practitioners. Eur. J. Dent. Educ. 2017, 21, 46-51. [CrossRef]

19. Leeheesu. The mediating effects of career related continuous learning(CRCL) on the relations between protean career attitudes and subjective career success. J. Voc. Educ. Res. 2015, 34, 25-50.

20. Liu, J. The impact mechanism of employee career planning on innovative behavior-From the perspective of organizational climate and risk tolerance. Leadersh. Sci. 2019, 14, 86-89.

21. Morland, K.V.; Breslin, D.; Stevenson, F. Development of a multi-level learning framework. Learn. Organ. 2019, 26, 78-96. [CrossRef]

22. Taylan, O. IT project risk assessment of learning organizations by fuzzy set and systems. Int. J. Organ. Anal. 2014, 22, 161-180. [CrossRef]

23. Douglas-Lenders, R.C.; Holland, P.J.; Allen, B. Building a better workforce: A case study in management simulations and experiential learning in the construction industry. Educ. Train. 2017, 59, 2-14. [CrossRef]

24. Scott, S.G.; Bruce, R.A. Determinants of innovative behavior: A path model of individual innovation in the workplace. Acad. Manag. J. 1994, 37, 580-607.

25. Li, J. Research on the Effect Mechanism between Innovation, Orientation, Organizational Climate and Knowledge Worker Innovation Behavior. Ph.D. Thesis, Jilin University, Changchun, China, 2016.

26. Amabile, T.; Conti, R.; Coon, H.; Lazenby, J.; Herron, M. Assessing the work environment for creativity. Acad. Manag. J. 1996, 39, 1154-1184.

27. Peng, H.; Zhang, W.; Zhang, X. Bank loan and political connection as well as bank relation of listed company: Empirical analysis on China's listed companies. Technol. Econ. 2013, 8, 87-94.

28. Riggs, M.L.; Warka, J.; Babasa, B.; Betancourt, R.; Hooker, S. Development and validation of self-efficacy and outcome expectancy scales for job-related applications. Educ. Psychol. Meas. 1994, 54, 793-802. [CrossRef]

29. Feng, X.; Jiang, R.; Peng, L. Research on the relationships between work motivation, perceived self-efficacy and employees' individual innovation behavior in Chinese service industry. $R$ D Manag. 2009, 21, 42-49.

30. Fornell, C.; Larcker, D.F. Evaluating structural equation models with unobservable variables and measurement error. J. Mar. Res. 1981, 18, 39-50. [CrossRef]

31. Wen, Z.; Hau, K.; Chang, L. A comparison of moderator and mediator and their applications. Acta Psychol. Sin. 2005, 37, 268-274.

32. Zhonglin, W.; Hongyun, L.; Jietai, H. Analysis of Moderating Effect and Mediating Effect; Education science Press: Beijing, China, 2012.

(C) 2020 by the authors. Licensee MDPI, Basel, Switzerland. This article is an open access article distributed under the terms and conditions of the Creative Commons Attribution (CC BY) license (http://creativecommons.org/licenses/by/4.0/). 